\title{
Leaving Home, Attending College, Partnership and Parenthood: The Role of Life Transition Events in Leisure Pattern Stability From Adolescence to Young Adulthood
}

\author{
Leslie A. Raymore, ${ }^{1}$ Bonnie L. Barber, ${ }^{2}$ and Jacquelynne S. Eccles ${ }^{3}$
}

Received September 29,1999; accepted October 28, 2000

Few researchers have examined the role that life transition events play in the maintenance of or change in leisure behaviors across the transition from adolescence to young adulthood. This study examines the role that leaving home, going to college, having a committed partner, and becoming a parent played in intraindividual change and stability in leisure patterns. The data were from the Michigan Study of Adolescent Life Transitions (MSALT), and were collected during the final year of high school and 3 years following high school. Results suggest that transition events are particularly useful in predicting female leisure pattern stability or change; going to college and leaving home were generally predictive of the maintenance of a stable leisure pattern, while becoming a partner and becoming a

\footnotetext{
This research was supported by grants from NSF, the Spencer Foundation and the William T. Grant Foundation to Eccles and Barber and grants from NICHD, NIMH, and NSF to Eccles.

${ }^{1}$ Senior Lecturer (equivalent to Associate Professor), Lincoln University in Christchurch, New Zealand. Received PhD in leisure studies from Pennsylvania State University. Research interests include developmental implications of leisure and constraints and facilitators to leisure. To whom correspondence should be addressed at Human Sciences Division, P.O. Box 84, Lincoln University, Canterbury, New Zealand.

${ }^{2}$ Associate Professor, family studies and human development, University of Arizona. Received PhD in developmental psychology from the University of Michigan in 1990 and served on the faculties of Pennsylvania State University and the University of Arizona. Research interests include adolescent social relationships across life transitions, and risk, resilience, and prevention in divorced families with adolescents.

${ }^{3}$ Wilber McKeachie Collegiate Professor of Psychology, Women's Studies, and Education, as well as a research scientist at the Institute for Social Research at the University of Michigan. Received $\mathrm{PhD}$ in developmental psychology from UCLA in 1974 and served on the faculties at Smith College, the University of Colorado, and the University of Michigan. Research interests include gender-role socialization, teacher expectancies, classroom influences on student motivation, and social development in the family and school context. Much of this work has focused on the middle childhood and adolescent periods.
} 
parent were predictive of change. For males, the most useful predictor of stability or change was leaving home. However, the nature of the relation of the transition events to pattern stability or change depended on the type of initial leisure pattern.

\section{INTRODUCTION}

Individuals add and delete leisure behaviors from their "leisure repertoire" across the life span. Changes in leisure behavior are most likely to occur during periods of life transition, when individuals' roles, relationships, and ecological contexts are altered. One major normative life transition is the shift from adolescence to young adulthood, when individuals leave behind so-called youthful freedom and begin to take responsibility for different aspects of their lives. Neither developmental nor leisure researchers have investigated how different events in the transition from adolescence to young adulthood affect leisure behavior. The goal of this study is to determine how leisure behavior patterns are influenced by the experience of 4 life transition events associated with the onset of young adulthood.

Leisure behavior is central to the two primary developmental tasks during adolescence, namely the formation of, and commitment to, an identity (Erikson, 1963), and the initial exploration of intimate relationships (Gilligan, 1982; Henderson, 1990). Leisure assists in these tasks as it provides an arena for role experimentation, assists in the learning of social norms, and provides a forum in which adolescents can experiment with the challenges they will face as adults (Fine et al., 1990; Iso-Ahola, 1980; Kleiber and Rickards, 1985).

Adolescent leisure behavior is related to a number of adult outcomes. For example, Otto and Featherman (1975) found that adolescents with higher involvement in extracurricular activities were more likely to be involved in voluntary organizations and political activities during adulthood; Eccles and Barber (1999) found that participation in extracurricular activities in the 10th grade predicted greater likelihood of college attendance; Otto and Alwin (1977) found that athletic participation in high school had a small, positive effect on adult income and educational and occupational achievement. Participation in certain activities during adolescence may therefore influence a number of pathways into adulthood, and may contribute to the increased heterogeneity observed as life progresses; adolescents who do not participate in certain forms of leisure may potentially have fewer pathways into and across adulthood.

During young adulthood the developmental need for an intimate relationship (Erikson, 1963) is likely to be reflected in young adults' leisure behavior (Kelly and Godbey, 1992; Kleiber and Rickards, 1985) via the leisure settings chosen by unattached young adults. However, the search for a partner is only one of many major changes that often occurs following high school graduation. According to 
Greene et al. (1992), there are 4 major life transition events associated with this period: Leaving home, which involves leaving the parental abode and becoming responsible for One's own residence; occupying an instrumental role, which may involve earning a paycheck or attending college full time; marriage, which requires the integration of two different people into a new household based on intimacy; and parenthood, which brings responsibility for another human being. Each of these transitions is likely to influence leisure behavior.

Of the 4 transition events, the influences of marriage and parenthood on leisure behavior have been studied most. Both getting married and parenthood increase the extent to which leisure behaviors take place at home (Crawford and Huston, 1993; Holman and Epperson, 1984; Rapoport and Rapoport, 1975; Witt and Goodale, 1981) and reduce involvement in risky behaviors such as substance use, especially for females (Kandel and Raveis, 1989). When individuals move toward marriage, friends and natal family generally recede into the background (Huston and Ashmore, 1985). The amount of leisure time spent with one's partner increases as the relationship progresses from serious dating to engagement to marriage; in contrast, the time spent on solitary leisure activities and on activities with others decreases (Surra, 1985). But research suggests that the pattern of these changes differs for males and females: Young women are more likely than males to either drop or decrease time spent on leisure activities with the onset of marriage (Crawford and Huston, 1993; Rapoport and Rapoport, 1975) and parenthood (Crawford and Huston, 1993; Horna, 1989).

Previous research also suggests that college attendance is associated with either maintenance or increased participation in leisure behavior. College provides a form of moratorium regarding identification with social institutions, as college students tend to experience the other 3 major transition events at a later date than non-college-students (Fasick, 1988; Sherrod et al., 1993). This slowing of the adoption of a number of adult roles allows college students to experiment with the roles and behaviors they may ultimately integrate into their lives. Sherrod et al. (1993), describing the state of knowledge regarding college attendance, concluded that "the developmental opportunities provided by this privilege are not well explored, but that half of the population not attending college may be missing more than continued academic achievement" (p. 219) because of the benefits accrued during the college moratorium period.

Hoff and Ellis (1992) suggested that the transition from high school to university life is highly beneficial to young adults' leisure because of a decrease in the number of constraints along with an increase in the number of facilities and the new world of peers, professors, and experiences unique to undergraduates. The university provides a near ideal environment for both cultivating new interests, and perfecting and consolidating leisure behaviors already chosen (Rapoport and Rapoport, 1975). Furlong et al. (1990), upon finding that late adolescents who were full-time students were involved in more recreational activity than late adolescents 
who were unemployed or working full time, concluded that students have an advantage in leisure because they have privileged access to sports, social, and cultural facilities, even though workers have more money. The college context may draw some students because of these leisure resources: Iso-Ahola and Buttimer (1981) found that university students had a higher leisure ethic and a lower work ethic than 12th graders. While college attendance may facilitate the maintenance of involvement in leisure behaviors, the responsibilities associated with college attendance may be related to a decline in time spent in leisure participation compared to adolescence. Berk and Goebel (1987) found an overall tendency of high leisure participants in high school to maintain greater levels of participation in college than do low leisure participants, although all students declined in their extracurricular participation from high school to college.

Relatively little is known about the long term influence of college attendance on leisure behavior following this period of social-role moratorium, although level of education has been found to be predictive of higher levels of activity involvement during middle adulthood (Freysinger and Ray, 1994). In general, research suggests that individuals who participate in a broad range of activities during high school are more likely to be involved in a broad range of leisure activities when they become young adults (Freysinger and Ray, 1994; Hendry, 1989; Lindsay, 1984). Perhaps high school students who are involved in a broad range of leisure activities are more likely to attend college, and are therefore more likely to be involved in higher levels of activity involvement later in life than are individuals who did not attend college.

College attendance may promote both socially valued and less acceptable forms of leisure behavior. Being a good student is related to less drinking in high school, yet in young adulthood, college attenders drink more than their noncollege age-mates (Crowley, 1991; Barnes et al., 1992; Schulenberg et al., 1994). These findings suggest that the change in context from high school to college may promote involvement in risky behaviors such as alcohol use.

Attending college or beginning to work often occurs around the same time as leaving home. Flanagan et al. (1993) concluded that living away from home marks an important transition point in human development. However, both the nature and influence of this transition event are understudied (Anderson and Fleming, 1986; Flanagan et al., 1993). In general, studies of the influence of leaving home focus on the experience of college students, and defining "leaving home" for college students can be difficult. Anderson and Fleming (1986) considered that a separate residence from parents indicates leaving home for college students, regardless of whether or not the students return to their parents' during vacations. People who go away to college have voluntarily left the nest and develop ties to a new community (Goldscheider and Davanzo, 1986) and must operate as independent adults, planning meals and budgeting both time and money (Zirkel and Cantor, 1990). The long term influence of leaving home on both college- and non-college-educated 
young adults' leisure behavior is unknown, although potential relations can be proposed based on related research.

Flanagan et al. (1993) found that college students who lived at home had less independence, lower respect for differences of opinion with their parents, and lower likelihood of a confidante relationship with parents, which the authors referred to as "mutuality." The young adults reported that one of the major problems with remaining at home was that their parents still treated them as if they were in high school. Females who resided with parents had higher levels of mutuality with, and greater support from, their parents than did males, which suggests that the behavior of females may be less likely to be affected by living at home during young adulthood.

In addition to psychosocial stresses, some evidence suggests that remaining at home during young adulthood may place leisure-related pressures on young adults. Aquilino and Supple (1991) found that in homes where young adults had not left home, sharing activities (including leisure) and spending enjoyable time together were positively related to parental satisfaction and negatively related to parental hostility. For young adults this may create a no-win situation, where spending a great deal of time with parents may constrict young adults' individual leisure expression, while spending too little time with parents may create an unhappy or hostile home environment.

To determine the influence of life transition events on leisure behavior pattern changes from adolescence to young adulthood, research participants need to be followed over time. However, few longitudinal studies exist where intraindividual comparisons of leisure behavior in general are made across any 2 or more points in the life span. The conclusions regarding the influence of the transition events accompanying the transition from adolescence to young adulthood on leisure behavior are generally based on cross-sectional research. Although age differences in leisure during young adulthood have been studied by a number of researchers (see Raymore, 1995), such research often compares two cohorts, usually individuals presently in high school and individuals presently in college, on their leisure behaviors. Additionally, when researchers have attempted to obtain within-subject data over time from married subjects, parents, or college students, they have often simply asked the subjects to recall their previous leisure behavior. Longitudinal studies are badly needed.

In summary, leisure provides an important arena for individual development during adolescence and young adulthood. While the transition from adolescence to young adulthood is accompanied by a number of contextual changes that should influence individual development, the influence of these changes on leisure behavior patterns has not been examined. The purpose of this study was to examine the role that the following major life events associated with the transition into young adulthood play in leisure behavior pattern stability: leaving home, attending college, marriage/partnership, and parenthood. 
Defining the point at which an individual becomes a young adult as opposed to remaining a late adolescent is, however, somewhat problematic (Arnett, 1998). While Fasick (1988) argues that graduation from high school demarcates the point of transition, other authors suggest that it is the adoption of adult social roles (e.g., marriage, full-time work) that indicate young adulthood. Young adults themselves see being financially independent and making autonomous decisions as primary markers of adulthood (Arnett, 1998). In this paper we treat young adulthood as the period following high school, when individuals are more likely to be making independent life decisions than they were during their high school years. Since the experience of life transition events is the focus of this study, the interpretation of results will involve the implications of the adoption of adult social roles.

The first step in addressing the purpose of the study involved the identification of leisure behavior patterns. In a previous study by the authors, information regarding the stability of patterns of leisure behavior was sought in order to determine the stability of different leisure "styles" or orientations (see Raymore et al., 1999). Cluster analyses were carried out to establish leisure behavior patterns at age 18 (12th grade) and at age 21 ( 3 years after high school). Because of the potential for differential effects of life transition events on males and females, all cluster analyses were carried out separately for each gender. Within gender, participants were randomly assigned to 1 of 2 groups to determine whether or not cluster solutions were replicable and reliable; all reliability coefficients were above $r=.70$. For an in-depth discussion of the cluster procedure and the solutions obtained see Raymore et al., 1999. Leisure pattern labels were based on cluster means for leisure behaviors relative to the means of other clusters within the same analysis. Similar labels across analyses denote similar but not necessarily identical patterns of leisure behavior. As these patterns form the foundation for the present study, a summary of the characteristics of the cluster solutions based on leisure activities is presented in Table I and patterns are described therein.

\section{Leisure Patterns}

\section{The Risky Leisure Pattern}

The Risky pattern was observed for females and males during both waves. Participants labeled as having a Risky pattern were most likely to be involved in leisure behaviors considered to put them at risk, such as drug and alcohol use and doing things "just for kicks."

\section{The Positive Active Leisure Pattern}

This pattern was apparent during adolescence for both males and females and during young adulthood for females. Participants who had the Positive Active 


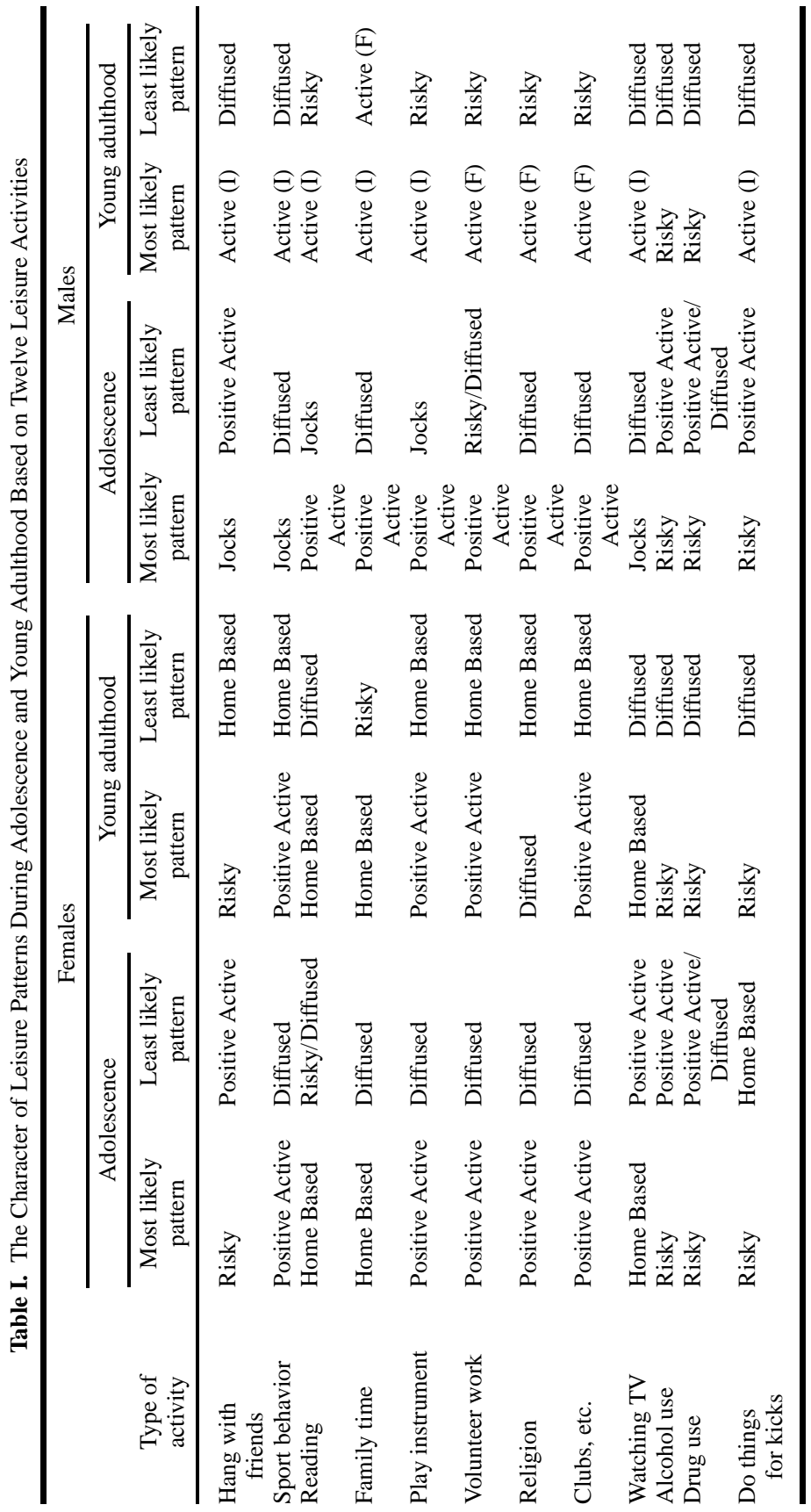


pattern were the most involved in a range of socially valued activities such as involvement in clubs or organizations, volunteer work, religion, and playing an instrument.

\section{The Active (Formal) and (Informal) Leisure Patterns}

These two clusters were present for males during young adulthood, and, as a pair, are complementary to the Positive Active pattern. Young adult males who had the Active (Formal) pattern spent the most time in volunteer work, religion, and clubs or organizations, while Active (Informal) males spent more time hanging out with friends, sports, reading, family, playing an instrument, watching television, and doing things for kicks than their peers did.

\section{The Diffused Leisure Pattern}

A Diffused leisure pattern was identified for both genders during both adolescence and young adulthood. Individuals in the Diffused pattern were not highest on any leisure behavior during either adolescence or young adulthood with one exception: Diffused young adult females were involved in religious activities at a higher rate than were female young adults in the other clusters. ${ }^{4}$ In addition, individuals in the Diffused pattern exhibited the fewest hours of participation on at least half of the behaviors during each wave. Therefore, whereas other leisure patterns were labeled based on high rates of participation in various activities, the Diffused cluster was defined by the members' lack of participation in activities (see Marcia, 1966).

\section{The Home Based Leisure Pattern}

The Home Based pattern was apparent for females during both adolescence and young adulthood. Females with this pattern reported the most time spent with family, reading, and watching television.

\section{The Jocks Leisure Pattern}

This pattern existed for males during adolescence. These adolescents hung out with their friends, were involved in sports, and watched television more frequently than their peers.

\footnotetext{
${ }^{4}$ The data suggested that religious females became Diffused in their leisure pattern during young adulthood, rather than the alternative explanation that Diffused females became religious.
} 
These patterns of leisure behavior during 12th grade and 2-3 years later provided the starting point from which to identify the role that life transition events play in leisure pattern stability across the late adolescent/early adulthood period.

\section{METHOD}

\section{Study Design and Sample}

The data reported herein are from Waves 6 and 7 of the Michigan Study of Adolescent Life Transitions (Raymore et al., 1999). MSALT data have been collected over 9 waves since 1983, the year prior to the participants making the transition into junior high school. The original population consisted of 6 th grade students from 10 predominantly white middle and lower middle class school districts in Southeastern Michigan. Wave 6 data were collected in the spring of 1990, when participants were in their senior year of high school. Wave 7 data were collected in 1992 and 1993, 2-3 years after the participants' senior year of high school; approximately $80 \%$ of eligible subjects participated in Wave 7 . The average age of participants was 18 years (representing late adolescence) and 21 years (representing young adulthood) at Wave 6 and 7 respectively.

Participants were included in the present study if they had participated in both waves of data collection. Based on this requirement, data existed for 602 females and 352 males.

\section{Measures}

During Wave 6 data collection, adolescents completed a 57-page questionnaire in their high school auditorium or cafeteria. No reward accompanied completion of the survey. Participants who were absent on the day of administration were sent the questionnaire with postage paid envelopes. During Wave 7, participants were mailed a questionnaire that was to be completed and returned by mail. Upon completion of the survey, participants were sent $\$ 20$.

Leisure patterns were based on involvement in twelve different leisure activities, as indicated previously in the description of the various patterns. The measurement of leisure items is described at length in Raymore et al., 1999.

Participants were considered to have experienced each of the four life transition events if, during Wave 7, they (1) were enrolled in college full time (college); (2) did not live in their parents residence, either permanently or during the academic year (left home); (3) were married, or had been living with their partner for at least 6 months (partner); or (4) identified themselves as having a child or step-child (parent). Table II presents a summary of the transition events of the sample by gender. 
Table II. Percent Experiencing Transition Events by Gender

\begin{tabular}{lcccc}
\hline & $\begin{array}{c}\text { Left } \\
\text { home }\end{array}$ & $\begin{array}{c}\text { Attending } \\
\text { college }\end{array}$ & $\begin{array}{c}\text { Had live-in } \\
\text { partner }\end{array}$ & $\begin{array}{c}\text { Became } \\
\text { parent }\end{array}$ \\
\hline Young adult females (\%) & 53 & 61 & 11 & 8 \\
Young adult males (\%) & 62 & 70 & 4 & 4 \\
\hline
\end{tabular}

Additional variables potentially related to leisure pattern during young adulthood were also included in the present analyses. Socioeconomic status was indicated by mother's occupation during Wave 7 using the socioeconomic index (SEI) (Entwisle and Astone, 1994). A ratio measure of work involvement was also included, where young adults indicated the total number of hours they spent working at each of their jobs.

\section{RESULTS}

Using the cluster solutions for adolescence and young adulthood, we determined the nature of the pathways between the 2 points in time and frequencies for each pathway (Raymore et al., 1999). For example, an adolescent female who was identified as having a Risky leisure behavior pattern during adolescence could have remained Risky in her pattern during young adulthood, or could have become either Positive Active, Diffused, or Home Based. The pathways of leisure behavior from adolescence into young adulthood are illustrated for females in Fig. 1 and for males in Fig. 2. Similar patterns during both periods represented a stable pathway from adolescence into young adulthood, while dissimilar pathways represented change, or instability, in leisure behavior pattern. For example, being Risky in leisure behavior during both adolescence and young adulthood indicated stability in leisure behavior pattern, while having a Risky leisure pattern during adolescence and Diffused leisure pattern during young adulthood indicated change or instability in leisure pattern.

\section{Influences on Life Transitions and Leisure Patterns}

Preliminary analyses were conducted to determine whether or not differences in the experience of transition events or leisure patterns were contingent upon other important differences between participants. Understanding these underlying relationships would aid in the interpretation of the results related to the purpose of the study. Adolescent leisure pattern, socioeconomic status, and work hours were examined. 
ADOLESCENCE

CLUSTER MEMBERSHIP
YOUNG ADULTHOOD

CLUSTER MEMBERSHIP
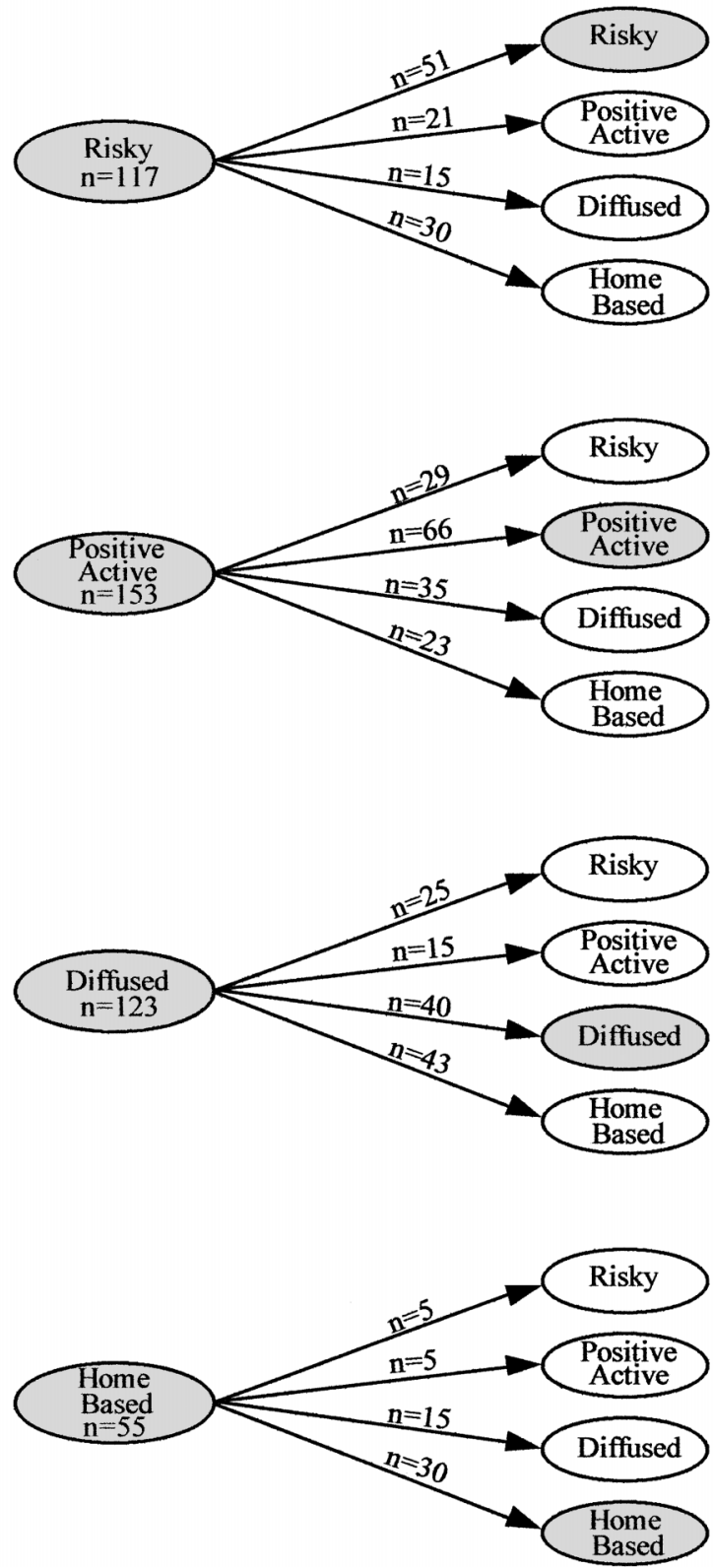

Fig. 1. Female leisure behavior pathways across the transition from adolescence to young adulthood $(N=448)$. 
ADOLESCENCE

CLUSTER MEMBERSHIP
YOUNG ADULTHOOD

CLUSTER MEMBERSHIP
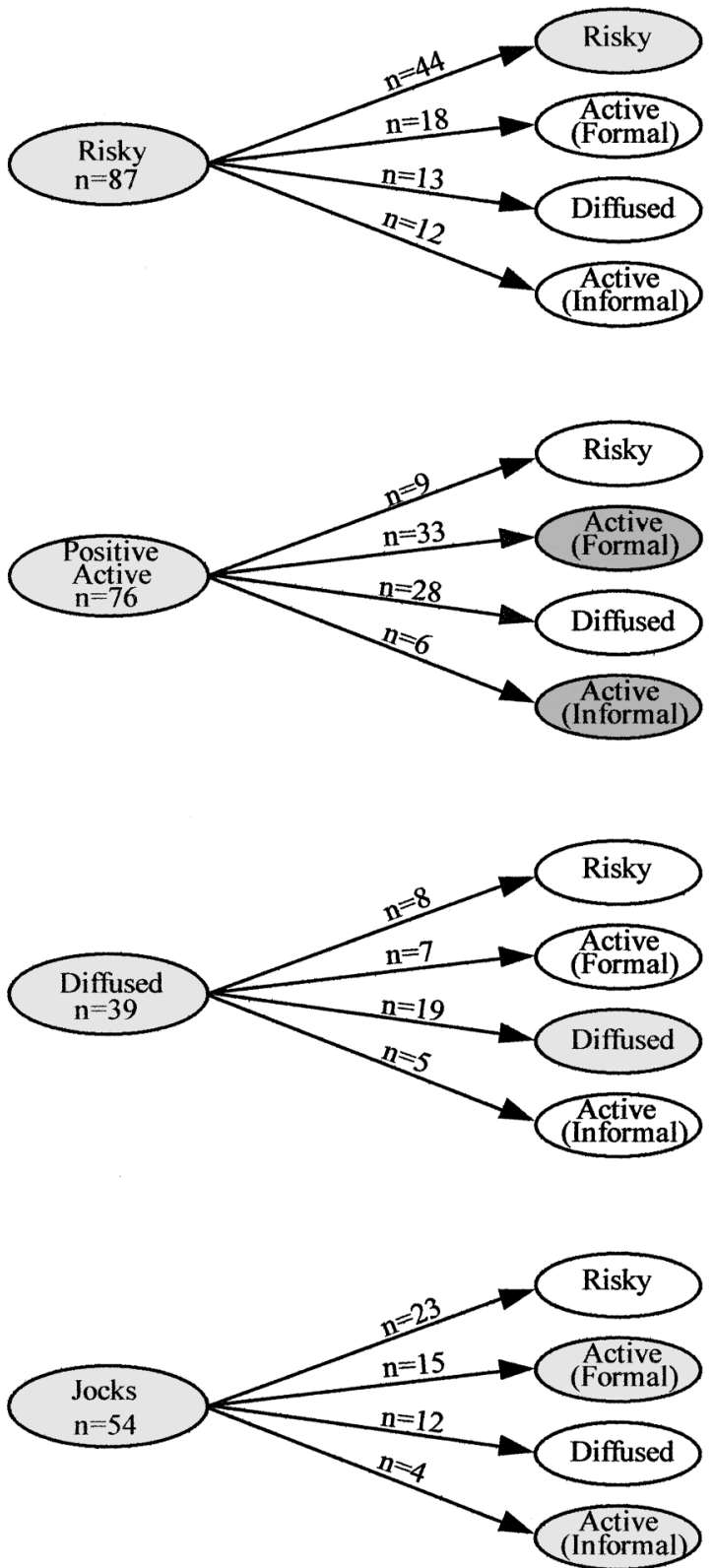

Fig. 2. Male leisure behavior pathways across the transition from adolescence to young adulthood $(N=256)$. 
Table III. Relationship Between Adolescent Leisure Pattern and the Experience of Life Transition Events

\begin{tabular}{|c|c|c|c|c|c|c|c|}
\hline \multirow{2}{*}{$\begin{array}{l}\text { Life transition } \\
\text { event }\end{array}$} & \multicolumn{5}{|c|}{$\%$ Experiencing transition event by adolescent leisure pattern } & \multirow{2}{*}{$\begin{array}{c}\chi^{2} \\
(\mathrm{df}=3)\end{array}$} & \multirow[b]{2}{*}{$p$} \\
\hline & Risky $^{a}$ & Positive Active $^{b}$ & Diffused $^{c}$ & Home Based ${ }^{d}$ & Jocks $^{e}$ & & \\
\hline \multicolumn{8}{|l|}{$\begin{array}{l}\text { Females } \\
\qquad(N=448)\end{array}$} \\
\hline Left home & 56 & 66 & 49 & 34 & & 22.65 & $<.001$ \\
\hline College & 58 & 85 & 51 & 35 & & 65.68 & $<.001$ \\
\hline Partner & 11 & 5 & 15 & 14 & & 9.86 & .02 \\
\hline Parent & 9 & 3 & 9 & 10 & & 6.20 & .10 \\
\hline \multicolumn{8}{|l|}{$\begin{array}{l}\text { Male } \\
\qquad(N=256)\end{array}$} \\
\hline Left home & 54 & 70 & 59 & & 67 & 4.94 & .18 \\
\hline College & 59 & 79 & 56 & & 83 & 16.09 & $<.01$ \\
\hline Partner $^{f+}$ & 8 & 4 & 0 & & 2 & 5.60 & .13 \\
\hline Parent $^{f+}$ & 9 & 3 & 0 & & 2 & 8.39 & .04 \\
\hline
\end{tabular}

\section{Adolescent Leisure Pattern and the Experience of Life Transition Events}

As adolescent involvement in certain forms of leisure behavior could potentially be associated with the likelihood of experiencing a life transition event during young adulthood, Table III reports the relationship between adolescent leisure activity patterns and the experience of each of the 4 life transition events.

For the females, adolescent leisure pattern was associated with both leaving home and college attendance; a greater number of Positive Active female adolescents than expected had left home and gone to college by age 21, while fewer Home Based adolescents had experienced the same transitions than would be expected. Females who had a Risky pattern during adolescence were more likely to have a partner during young adulthood, while Positive Active female adolescents were less likely to have experienced this transition during young adulthood than would be expected. Being a parent at young adulthood was not significantly related to adolescent leisure behavior pattern for females.

Adolescent male leisure pattern was associated only with college attendance during young adulthood; males who had been Risky during adolescence were the least likely to have gone to college while Positive Active males were the most likely group to experience this transition. Assessment of any relation between adolescent leisure pattern and partnership or parenthood was not possible for the males because of low frequencies of occurrence. 
Table IV. Relationship Between Socioeconomic Index Score and the Experience of Transition Events

\begin{tabular}{|c|c|c|c|c|c|c|c|c|c|}
\hline & \multicolumn{3}{|c|}{ Experienced transition } & \multicolumn{3}{|c|}{ Did not experience transition } & \multirow[b]{3}{*}{ df } & \multirow[b]{3}{*}{$t$} & \multirow[b]{3}{*}{$p$} \\
\hline & \multirow[b]{2}{*}{$N$} & \multicolumn{2}{|c|}{ SEI score } & \multirow[b]{2}{*}{$N$} & \multicolumn{2}{|c|}{ SEI score } & & & \\
\hline & & $M$ & SD & & $M$ & SD & & & \\
\hline \multicolumn{10}{|l|}{ Female } \\
\hline Left home & 161 & 51.22 & 17.23 & 139 & 45.76 & 16.01 & 298 & 2.82 & .005 \\
\hline Attending college & 189 & 50.84 & 16.45 & 111 & 45.03 & 16.95 & 298 & 2.91 & .004 \\
\hline Had live-in partner & 30 & 41.80 & 16.80 & 257 & 49.61 & 16.85 & 285 & 2.4 & .02 \\
\hline Became parent & 23 & 43.50 & 15.62 & 277 & 49.12 & 16.96 & 298 & 1.54 & .13 \\
\hline \multicolumn{10}{|l|}{ Males } \\
\hline Left home & 108 & 54.76 & 16.4 & 57 & 46.85 & 18.23 & 163 & 2.74 & .007 \\
\hline Attending college & 118 & 52.98 & 17.92 & 47 & 49.63 & 18.07 & 163 & 1.08 & .28 \\
\hline Had live-in partner & 9 & 41.61 & 16.19 & 155 & 52.78 & 17.89 & 162 & 1.83 & .07 \\
\hline Became parent & 8 & 37.76 & 15.61 & 156 & 52.69 & 17.86 & 162 & 2.32 & .02 \\
\hline
\end{tabular}

\section{Socioeconomic Status}

Mother's occupation (SEI index of socioeconomic status) at Wave 7 was examined in relation to the experience of each of the life transition events (Table IV). Participants who either failed to report mother's occupation or who were not specific enough in their answer (e.g., "other work") were not included in this analysis. Mean SEI scores for females and males were 48.69 and 52.02 respectively. A score of 49 corresponds to occupations such as sales support and protective service, and a score of 52 corresponds to occupations such as office supervisors and artists. The lowest maternal occupations for females and males was represented by the score 21.21 (maid) while the highest was 85.06 for the females (education administrator) and 92.30 for the males (lawyer).

The likelihood of experiencing each of the transition events based on SEI was first examined for females. Females who had left home were from higher SEI backgrounds than were females who had not left home. Females who attended college were from higher SEI families than were females who did not attend college. Young adult females who had partners tended to be from lower SEI families than did females who did not have partners, but there was no significant relation between SEI and parenthood for the females. However, caution should be exercised when interpreting the partnership and parenthood variables because of the low numbers of females who experienced these life transition events.

Similar results were found for the males; those participants who had left home were from backgrounds of higher SEI than were students who had not left home. However, there was no difference in SEI between males who were or were not in college full time. Partnership approached significance in its relationship to SEI; parenthood was significantly related. Male participants who had partners or who were parents tended to be of lower SEI than did those who had not experienced 
these transitions. Again, because of problems with the small number of males experiencing these transitions caution should be exercised when interpreting these results.

Closer inspection of the relation of leaving home to SEI revealed an interaction based on college attendance for both the males and the females. In the case of noncollege participants there was no difference in SEI between those who had and those who had not left home. In the case of college students, females who had left home were from higher SEI homes $(N=115, M=54.7, \mathrm{SD}=16.5)$ than college females who had not left home $(N=74, M=44.8, \mathrm{SD}=14.8)(t=$ 4.19 , df $=187, p<.001)$. The same was true for college males who had left home $(N=86, M=55.7, \mathrm{SD}=17.8)$ compared to college males who had not left home $(N=32, M=45.8, \mathrm{SD}=16.3)(t=2.74, \mathrm{df}=116, p=.007)$.

\section{Relation of Work Hours to Leisure Pattern}

To understand better the activities of those who did not make the transition to college, work hours of the noncollege participants were examined. In addition, the involvement in paid work was compared across young adult leisure patterns.

A large majority of noncollege young adults were employed ( $82 \%$ of females, 94\% of males). An ANOVA with the noncollege males indicated that significant differences in total work hours existed among the different leisure patterns during young adulthood $(N=70, \mathrm{df}=3,67, F=3.45, p=.02)$. A Tukey-B follow up test indicated that the Diffused males worked significantly $(p=.05)$ less hours $(M=34.4, \mathrm{SD}=16.2)$ than those males with the Risky pattern did $(M=50.8, \mathrm{SD}=19.3)$. Males from the Diffused cluster had the lowest mean hours at work of all of the 4 leisure patterns. There were no significant differences among the 4 female leisure patterns in the total hours spent at work during young adulthood.

There were no differences in total hours worked between the 4 leisure patterns of the males or the females who attended college.

\section{Leisure Pattern Stability, Instability, and Life Transition Events}

Discriminant analyses were performed using the 4 life transition events as predictor variables to discriminate between leisure behavior pathways from adolescence to young adulthood. As each of the predictor variables was dichotomous, dummy coding $(0,1)$ was used, with 1 assigned to those who experienced the transition. Each of the pathways from the adolescent pattern to the young adulthood pattern was examined for stability versus change; discriminant analyses were carried out first using the pathway or outcome group identified as 
Table V. Correlations Between Transition Events by Gender

\begin{tabular}{lcccc}
\hline & Left home & Attending college & Had live-in partner & Became parent \\
\hline Females & & & & \\
$\quad$ Left home & 1.0 & & & \\
$\quad$ Attending college & $.214^{*}$ & 1.0 & 1.0 & 1.0 \\
$\quad$ Had live-in partner & $.179^{*}$ & $-.388^{*}$ & $.457^{*}$ & \\
$\quad$ Became parent & .0315 & $-.309^{*}$ & & \\
Males & & & & \\
$\quad$ Left home & 1.0 & & & \\
$\quad$ Attending college & $.270^{*}$ & 1.0 & .0 & 1.0 \\
Had live-in partner & .086 & $-.283^{*}$ & & \\
Became parent & .085 & $-.283^{*}$ & & \\
${ }^{*} p \leq .001$. & & & &
\end{tabular}

stable compared to all the other possible pathways from that adolescent pattern. For example, the Positive Active adolescent females who remained Positive Active during young adulthood (stable path) were discriminated from females who changed to any of the other possible patterns (Risky, Diffused, Home Based) during young adulthood (unstable) on the basis of the 4 life transition events. Next, a similar procedure pairing the stable pathway with each of the nonstable pathways or outcome groups per analysis (e.g., Positive Active stable vs. Positive Active to Risky) was performed to increase the interpretability of the individual patterns.

A number of the predictor variables were significantly correlated (see Table V). The lack of unique variability across some pairs of variables suggests that caution should be exercised when interpreting the results of single predictor variables. Although discriminant analysis does not solve this problem, the procedure does estimate the effects of each predictor variable or life transition event separately when indicating the correlation of those variables to a discriminant function (i.e., the structure coefficient). Variables that are highly correlated should have similar structure coefficients, but the correlation between two predictor variables does not reduce the interpretability of the results via multicollinearity.

Table VI provides relevant statistical information for the discriminant functions that were significant, and Table VII presents a summary of the group centroids and structure coefficients for these significant discriminant functions. Predictor variables are reported if the difference between the two groups in the discriminant analysis on the predictor variable was at least approaching significance $(p \leq .10)$. Press's $Q$ statistic, reported in Table VI, is a measure of the likelihood that the predictions based on the discriminant functions were based on chance. The results indicate that for each of the significant discriminant functions the predictions were significantly better than those that would be expected based on chance. 
Table VI. Statistics for Significant Discriminant Functions

\begin{tabular}{|c|c|c|c|c|c|c|}
\hline Transitions & $n$ & $\begin{array}{l}\text { Significance } \\
\text { of function }\end{array}$ & $\chi^{2}(\mathrm{df}=4)$ & $\eta$ & $\begin{array}{l}\text { \% Correctly } \\
\text { classified }\end{array}$ & $\begin{array}{l}\text { Press's } Q^{a} \\
\text { statistic }\end{array}$ \\
\hline \multicolumn{7}{|l|}{ Female } \\
\hline \multicolumn{7}{|l|}{ Risky to } \\
\hline Risky $^{b}$ & 49 & .049 & 9.53 & .15 & 77.3 & 18.78 \\
\hline Diffused & 14 & & & & & \\
\hline Risky $^{b}$ & 49 & .007 & 14.27 & .18 & 66.2 & 8.08 \\
\hline Home Based & 28 & & & & & \\
\hline \multicolumn{7}{|l|}{ Positive Active to } \\
\hline Positive Active $^{b}$ & 66 & .01 & 13.15 & .13 & 70.0 & 16.00 \\
\hline Diffused & 34 & & & & & \\
\hline Positive Active $^{b}$ & 66 & $<.001$ & 26.17 & .27 & 81.6 & 34.74 \\
\hline Home Based & 21 & & & & & \\
\hline Positive Active $^{b}$ & 66 & .005 & 14.72 & .10 & 62.4 & 9.11 \\
\hline $\begin{array}{l}\text { All unstable who } \\
\text { were Positive }\end{array}$ & 83 & & & & & \\
\hline Active adolescents & & & & & & \\
\hline \multicolumn{7}{|l|}{ Home Based to } \\
\hline Home Based ${ }^{b}$ & 29 & .01 & 13.47 & .36 & 82.4 & 14.26 \\
\hline Positive Active & 5 & & & & & \\
\hline Home Based ${ }^{b}$ & 29 & $.07^{c}$ & 8.61 & .20 & 72.1 & 9.01 \\
\hline Diffused & 14 & & & & & \\
\hline Home Based ${ }^{b}$ & 29 & $.07^{c}$ & 8.62 & .16 & 67.9 & 6.80 \\
\hline $\begin{array}{l}\text { All unstable who } \\
\text { were Home Based } \\
\text { adolescents }\end{array}$ & 24 & & & & & \\
\hline \multicolumn{7}{|l|}{ Male } \\
\hline \multicolumn{7}{|l|}{ Positive Active to } \\
\hline Active $(\mathrm{F} \& \mathrm{I})^{b}$ & 39 & .03 & 10.54 & .17 & 68.7 & 9.37 \\
\hline Diffused & 28 & & & & & \\
\hline Active $(\mathrm{F} \& \mathrm{I})^{b}$ & 39 & .05 & 9.56 & .13 & 65.3 & 7.03 \\
\hline $\begin{array}{l}\text { All unstable who } \\
\text { were Positive } \\
\text { Active adolescents }\end{array}$ & 36 & & & & & \\
\hline \multicolumn{7}{|l|}{ Jocks to } \\
\hline Active (F\&I) & 19 & $.09^{c}$ & 6.50 & .21 & 74.2 & 7.26 \\
\hline Diffused & 12 & & & & & \\
\hline
\end{tabular}

${ }^{a}$ All $Q$ Statistics were significant $(p<.01)$.

${ }^{b}$ Indicates stable path.

${ }^{c}$ Approaching significance.

\section{Predicting Female Leisure Pattern Stability or Change}

\section{Risky Adolescent Females}

The function discriminating between remaining Risky in young adulthood as compared to changing to any other pattern was not significant. The most common pattern for those females who had been Risky during adolescence but who changed during young adulthood was to become Home Based. 
Table VII. Structure Coefficients for Significant Discriminant Functions

\begin{tabular}{|c|c|c|c|c|c|}
\hline \multirow[b]{2}{*}{$\begin{array}{l}\text { Leisure pattern from adolescence } \\
\text { into young adulthood }\end{array}$} & \multicolumn{5}{|c|}{ Structure coefficients } \\
\hline & $\begin{array}{l}\text { Group } \\
\text { centroid }\end{array}$ & $\begin{array}{l}\text { Leaving } \\
\text { home }\end{array}$ & $\begin{array}{l}\text { Going to } \\
\text { college }\end{array}$ & $\begin{array}{c}\text { Having a } \\
\text { partner }\end{array}$ & $\begin{array}{l}\text { Being a } \\
\text { parent }\end{array}$ \\
\hline \multicolumn{6}{|l|}{ Females } \\
\hline \multicolumn{6}{|l|}{ Risky adolescents } \\
\hline Risky to Risky & -.22 & $-.52^{a}$ & .13 & .21 & $.59^{a}$ \\
\hline Risky to Diffused & .77 & & & & \\
\hline Risky to Risky & -.35 & -.39 & $-.73^{b}$ & $.51^{b}$ & $.74^{b}$ \\
\hline Risky to Home Based & .61 & & & & \\
\hline \multicolumn{6}{|l|}{ Positive Active adolescents } \\
\hline Positive Active to Positive Active & .27 & $.92^{b}$ & $.49^{a}$ & .19 & -.13 \\
\hline Positive Active to Diffused & -.53 & & & & \\
\hline Positive Active to Positive Active & .34 & $.32^{a}$ & $.91^{b}$ & $-.67^{b}$ & $-.44^{b}$ \\
\hline Positive Active to Home Based & -1.1 & & & & \\
\hline Positive Active to Positive Active & .36 & $.75^{b}$ & $.77^{b}$ & -.20 & -.41 \\
\hline Positive Active to any unstable pattern & -.29 & & & & \\
\hline \multicolumn{6}{|l|}{ Home Based adolescents } \\
\hline Home Based to Home Based & -.30 & .02 & $.99^{b}$ & -.23 & -.17 \\
\hline Home Based to Positive Active & 1.76 & & & & \\
\hline Home Based to Home Based & -.34 & -.50 & .48 & .31 & -.08 \\
\hline Home Based to Diffused ${ }^{c}$ & .70 & & & & \\
\hline Home Based to Home Based & -.39 & -.43 & $.74^{b}$ & -.15 & .08 \\
\hline Home Based to any unstable pattern ${ }^{c}$ & .47 & & & & \\
\hline \multicolumn{6}{|l|}{ Males } \\
\hline \multicolumn{6}{|l|}{ Positive Active adolescents } \\
\hline Positive Active to Active (general) & .36 & $.76^{b}$ & -.08 & .09 & .35 \\
\hline Positive Active to Diffused & -.50 & & & & \\
\hline Positive Active to Active (general) & .36 & $.79^{b}$ & -.04 & .16 & .42 \\
\hline Positive Active to any unstable pattern & -.39 & & & & \\
\hline \multicolumn{6}{|l|}{ Jock adolescents } \\
\hline Jocks to Active (general) & .40 & $.76^{b}$ & -.46 & -.46 & .38 \\
\hline Jocks to Diffused $^{c}$ & -.63 & & & & \\
\hline
\end{tabular}

${ }^{a}$ Difference in means between stable and unstable paths approaching significance $(p \leq .10)$.

${ }^{b}$ Difference in means between stable and unstable paths significant $(p \leq .05)$.

${ }^{c}$ Approaching significance.

Further analyses revealed that leaving home and being a parent were useful in the prediction of remaining stable in the Risky pattern compared to becoming Diffused during young adulthood. Females who remained Risky were 20\% more likely to have left home than were those Risky adolescents who became Diffused young adults. In addition, females who became Diffused were 5 times more likely to have become parents than were those who remained stable in their Risky leisure.

Attending college, not having a partner, and not becoming a parent were all predictive of stability in Risky leisure behavior compared to the unstable path of becoming Home Based. Females who remained stable as Risky were almost twice as likely to have gone to college as those Risky adolescents who became Home Based; these Home Based young adult females were 3 times as likely to have a 
partner and 5 times more likely to have become a parent as the stable Risky leisure females. As mentioned previously, becoming Home Based was the most likely path into young adulthood for females with unstable leisure patterns who had been Risky during adolescence.

\section{Positive Active Adolescent Females}

Positive Active adolescent females were predicted to remain stable during young adulthood on the basis of whether they had left home or had gone to college. Females who remained stable in a Positive Active leisure pattern were almost $25 \%$ more likely to have left home and were almost $20 \%$ more likely to have gone to college than were those females who changed to a different pattern during young adulthood after being Positive Active during adolescence. The most common pattern for the females who changed from Positive Active was to become Diffused.

The association of these transition events was also found on closer inspection when the ability to predict stability in the Positive Active pattern versus change to the Diffused pattern during young adulthood was examined. Again, Positive Active adolescent females who became Diffused young adults were $25 \%$ more likely to be living at home and almost $15 \%$ less likely to attend college than their stable Positive Active counterparts.

Each of the four life transition events was useful in discriminating between remaining Positive Active versus becoming Home Based. Females who became Home Based were $40 \%$ less likely to be in college, $20 \%$ less likely to have left home, eight times more likely to have a partner and almost fifteen times more likely to be a parent than females who remained Positive Active in their leisure behavior during young adulthood.

\section{Diffused Adolescent Females}

None of the discriminant functions predicting stability in the Diffused leisure patterns versus other pathways was significant. The most common path into young adulthood from being a Diffused female during adolescence was to become Home Based. This path was the only instance where a specific unstable path into young adulthood was more common than the stable path.

\section{Home Based Adolescent Females}

College attendance was the main predictor for discriminating between stability and change in the Home Based adolescent leisure pathways. The overall 
stable versus change analysis approached significance. While only $20 \%$ of those females who remained stable in their Home Based leisure went to college, $48 \%$ of those who changed patterns from being Home Based attended college. The most common path of change was to become Diffused.

The number of females who were Home Based in their leisure during adolescence and who became Positive Active during young adulthood was relatively small $(n=5)$. However, $100 \%$ of those females who became Positive Active after a history of being Home Based attended college. Only $20 \%$ of the stable Home Based females attended college, as mentioned previously.

The discriminant analysis based on remaining stable as Home Based or becoming Diffused during young adulthood approached significance, but none of the life transition events were significant predictors of stability versus change. As indicated previously, becoming Diffused was the most likely pathway into young adulthood leisure behavior for those females with unstable patterns. The Home Based pattern was clearly the most stable of all leisure patterns for females.

\section{Predicting Male Leisure Pattern Stability or Change}

\section{Risky Adolescent Males}

The 4 life transition events were not useful in discriminating between the stable Risky path and all other paths, the Active path, where Active (Informal) and (Formal) were combined to represent Active (General), or the Diffused path. The most common unstable path into young adulthood for males who were Risky adolescents was to become Active (General); this path was 2 times more likely than the Diffused path.

\section{Positive Active Adolescent Males}

A significant discriminant function was obtained when the 4 life transition events were used to predict stability in a Positive Active pattern compared to changing to Risky or Diffused, where Active (Formal) and Active (Informal) are combined to represent an Active (General) pattern. The most useful predictor was leaving home; $57 \%$ of those participants who became Risky or Diffused in their pattern had not left home. In contrast, $82 \%$ of the participants who remained stable as Positive Active had left home.

Leaving home was a useful predictor in discriminating between remaining stable as Positive Active versus becoming Diffused during young adulthood. This pattern was the most likely path into young adulthood for unstable Positive Active males, who were 3 times as likely to become Diffused as opposed to Risky. 


\section{Diffused Adolescent Males}

Life transition events were not useful in discriminating leisure pathways from adolescence to young adulthood for stable Diffused males compared to all other pathways: becoming Risky, and becoming Active (General). The parent and partner variables were dropped from these analyses because of low frequencies of occurrence. The most common path for males who were Diffused during adolescence but who changed leisure patterns during young adulthood was to become Active (General), although this was not a clear majority.

\section{Adolescent Jock Males}

Stability of the Jock males could not be determined, since the Jock cluster did not exist during young adulthood. However, a discriminant analysis examining the predictive ability of the 4 life transition events in discriminating between Jocks becoming Active (General) as opposed to Diffused approached significance. Leaving home was a useful predictor of becoming Active (General) compared to becoming Diffused. Eighty-four percent of those who became Active (General) and $50 \%$ of those who became Diffused had left home.

The most common pathway into young adulthood for males who had been Jocks during adolescence was to become Risky.

\section{DISCUSSION}

\section{The Role of Life Transition Events and Accompanying Changes in Context in Leisure Pattern Stability}

These results suggest that the contextual changes that accompany the onset of young adulthood, via the experience of life transition events, play an important role in the stability or change in leisure patterns of young adults.

\section{Leaving Home}

Adolescent females who were Positive Active during adolescence were the most likely to have left home during young adulthood, but for males there was no relationship between home leaving and adolescent leisure pattern. Leaving home was unrelated to SEI for both males and females who had not gone to college, and for males who attended college. Female college students, however, were more likely to live at home if they were from low SEI backgrounds.

Leaving home was predictive of stability in leisure pattern for participants who had the Positive Active pattern during adolescence - for both sexes — if we consider the male pattern of Active (General) to be a permutation of Positive Active. As 
indicated previously, relatively little is known about the effects of leaving home on leisure behavior. The present study suggests, however, that there may be something about residing in the parental home environment that limits participation in the leisure activities we examined during young adulthood, based on the interpretation of becoming Diffused representing a drop in leisure involvement. The Diffused pattern, however, may simply consist of people who do not participate in a pattern of leisure activities or in the activities included in this study. Alternatively, one may surmise that Diffused individuals spend more time at work and are therefore unable to be involved in leisure. The results, however, suggested that there were no differences between leisure patterns in the time spent at work for females during young adulthood, while Diffused males during this period of life worked the fewest hours of any of the leisure patterns.

Leaving home was the strongest predictor in the maintenance of a stable Positive Active pattern as opposed to becoming Diffused, for both males and females. Changing from a highly involved pattern to a lowly involved pattern may be the result of pressure from parents to spend leisure time with them (Aquilino and Supple, 1991). The independence associated with living away from home during young adulthood may facilitate the continuation of high involvement in the community and a range of other activities.

While the relationship between leaving home and college attendance is strong, the different pattern of results for these two transition events suggests that leaving home has an effect distinct from that of going to college.

\section{Going to College}

Going to college was not predictive of change or stability in any leisure behavior pattern for males. For females, going to college was predictive of maintaining a stable Risky pattern compared to becoming Diffused or Home Based, as well as maintaining a Positive Active pattern as opposed to becoming Diffused or Home Based.

Both the Risky and Positive Active patterns may be substantively different from the Home Based and Diffused patterns because the types of leisure behavior they involve may be more likely to occur in a social context. For females, not going to college may precipitate a reduction in leisure behavior involving other people, perhaps because of the loss of social context identified by Furlong et al. (1990). While Hoff and Ellis (1992) suggested that the transition from high school to college is, in general, beneficial to young adults' leisure, the present study suggests that going to college benefits the leisure behavior patterns of females but not of males. Further, the results suggest that these benefits are more likely to be accessed by females from higher SEI backgrounds.

An alternative explanation for the increased likelihood of noncollege females becoming Diffused or Home Based may be that work commitments reduced the 
time they had available for leisure. However, since there was no significant difference between the 4 patterns of leisure with regard to the time spent at work, becoming Diffused or Home Based seems to be more related to the lack of the student context than to work involvement.

\section{Entering a Romantic Partnership}

Becoming a partner was not found to be predictive of stability or change in leisure behavior pattern for males for any of the patterns. For females, however, becoming a partner was predictive of changing from being Positive Active during adolescence to becoming Home Based during young adulthood. For females, therefore, being married or living with a partner for at least 6 months appears to result in a shift from being highly involved in organizations, volunteer activities, religion and sports to spending time with family, watching TV, and reading. This finding is consistent with the literature that suggests that being in a long term relationship has differential effects on the leisure of males and females, and that the principal impact is a decrease in leisure outside the home for females (Crawford and Huston, 1993).

For Positive Active female adolescents, having a partner during young adulthood was related to remaining stable as opposed to becoming Diffused. Although there was not a significant difference in rates of partnership between the stable and changed groups, the results suggest that Positive Active females may attract partners that facilitate or do not impede the maintenance of a Positive Active leisure pattern. Interestingly, none of the 39 males who had been Diffused in their leisure pattern during adolescence experienced the life transition of having a partner during young adulthood.

Becoming a partner, however, was the least predictive of the 4 transition events for changing from Positive Active to becoming Home Based, and having a partner was not predictive of change versus stability in any of the other leisure patterns. Therefore, while becoming involved in a committed relationship may lead to changes in the leisure behavior of some females (particularly those who were previously highly active in socially valued activities), in general this life transition event was not predictive of remaining stable in, or changing, one's leisure pattern. Caution should be exercised when interpreting the influence of partnership on leisure pattern stability and change, since relatively few participants $(11 \%$ of females, $4 \%$ of males) experienced this life transition event, and the leisure activities in this study do not include spending time with a partner.

\section{Becoming a Parent}

Becoming a parent was not predictive of stability or change in any of the male patterns. The finding that parenthood did not appear to have an influence 
on the maintenance of, or change in, male leisure patterns is consistent with the suggestion that the leisure of males is less likely to be affected by parenthood than that of females (Crawford and Huston, 1993; Horna, 1989).

Females who were Positive Active during adolescence and who experienced the transition event of becoming a parent could be predicted to become Home Based. As women involved in clubs, volunteer activities, and other socially valued activities became parents, their leisure behavior tended to shift into the home and include television, reading, and, not surprisingly, spending time with family.

Females who had the Risky pattern during adolescence were likely to change to being Diffused if they had become parents. This finding - that females may be likely to stop using alcohol and drugs and doing things "just for kicks" as they become parents-is consistent with previous work that suggests that females are more likely to reduce their involvement in risky behaviors as they adopt adult social roles such as parenthood. (Bachmanl et al., 1997; Kandel and Raveis, 1989)

Again, the interpretability of the role parenthood plays in stability or change in leisure patterns may have been affected by the low frequency of occurrence, since relatively few participants ( $8 \%$ of females, $4 \%$ of males) experienced this life transition event.

\section{General Observations Regarding the Prediction of Stability and Change}

It should be noted that, in general, stability in leisure pattern was the most common pathway into young adulthood. While this could be interpreted as suggesting that adolescent leisure patterns may be the only meaningful predictor of leisure pattern at young adulthood, only $42 \%$ of females and $50 \%$ of males were stable in their leisure pattern from adolescence to young adulthood (i.e., where a stable path could be identified).

The results clearly suggest that, for females, the role that life transition events play in predicting stability or change in leisure behavior pattern depends on the type of pattern experienced during adolescence as well as the type of transition experienced. For example, all 4 life transition events (leaving home, going to college, not having a partner, not becoming a parent) were important in predicting whether a Positive Active adolescent remained stable during her young adulthood or became Home Based. However, the only useful predictor of becoming Positive Active after being Home Based during adolescence was going to college. In fact, every female who changed from having a pattern identified by high levels of television, reading, and family time during adolescence to a pattern of high involvement in clubs, volunteer work, and sports during young adulthood went to college.

Male stability and change in leisure pattern could not be predicted for any of the patterns by college attendance, having a partner, or being a parent. The only useful predictor of leisure pattern stability or change for males was leaving home, and this event was a useful predictor in only 3 types of change. 
The overall pattern of results in this study suggests that female leisure patterns are more dependent on the contextual variables that accompany the transition from adolescence to young adulthood than male leisure behavior patterns. This sample, however, consisted of primarily white, lower middle and middle class participants. The leisure behavior patterns discussed herein and the influence of life transition events on leisure behavior may not apply to people from other ethnic and socioeconomic backgrounds.

It is essential to note that maternal SES played an important role in determining the experience of transition events that ultimately influenced leisure patterns. For example, leaving home during young adulthood was an important transition for both males and females with Positive Active patterns during adolescence, yet young adults from low SES families were less likely to have left home. Further research is needed to determine whether or not the apparent "protective" effects of maternal SES on leisure patterns in the early years of young adulthood continue to benefit individuals later in the young adulthood period.

This study examined the role of normative life transition events in predicting stability or change in leisure behavior during adolescence and young adulthood. This period in the life span may be unique from others in the way that people incorporate life transition events into their leisure lifestyle. For example, having children a decade later in the life span may have a completely different effect on leisure. Also, the long term influence of the life transition variables on leisure behavior may not be the same as the influence that appears to have occurred during the two points in time in the present study. For example, attending college was related to leisure pattern stability for Risky and Positive Active females. Do the stabilizing effects of attending college continue to influence leisure patterns beyond the college years, or do they disappear with college leaving? Does college graduation mediate the influence of parenthood and partnership on female leisure pattern stability?

Finally, this study examined predictors of stability and change in leisure behavior pattern. While some patterns could not be predicted to remain stable or to change based on life transition events, the results suggest that people with certain patterns of leisure behavior may be more or less likely to experience certain life transition events within the 2-3 years following high school. Further research should examine the avenues through which adolescent leisure behavior pattern can influence the onset of life transition events.

\section{ACKNOWLEDGMENTS}

We wish to thank the following people for their contributions to this project: Carol Midgley, Allan Wigfield, Janis Jacobs, Constance Flanagan, Christy Miller Buchanan, Andrew Fuligni, Deborah Josefowicz, Pam Frome, Lisa Colarossi, Laurie Meschke, and Kristen Jacobson. We are also grateful to Geof Godbey and 
Margaret Stone for their comments on the manuscript and to Craig Edelbrock for his help with the cluster analyses.

\section{REFERENCES}

Anderson, S. A., and Fleming, W. M. (1986). Late adolescents' home-leaving strategies: Predicting ego identity and college adjustment. Adolescence 82: 453-459.

Aquilino, W. S., and Supple, K. R. (1991). Parent-child relations and parent's satisfaction with living arrangements when adult children live at home. J. Marr. Fam. 53: 13-27.

Arnett, J. J. (1998). Learning to stand alone: The contemporary American transition to adulthood in cultural and historical context. Human Devel. 41: 295-315.

Bachman, J. G., Wadsworth, K. N., O’Malley P. M., Schulenberg, J., and Johnson, L. D. (1997). Marriage, divorce, and parenthood during the transition to young adulthood: Impacts on drug use and abuse. In Schulenberg, J., and Maggs, J. L. (eds.), Health Risks and Developmental Transitions During Adolescence. Cambridge University Press, New York, pp. 246-279.

Barnes, G. M., Welte, J. W., and Dintcheff, B. A. (1992). Alcohol misuse among college students and other young adults: Findings from a general population study in New York State. Int. J. Addict. 27(8): 917-934.

Berk, L., and Goebel, B. (1987). Patterns of extracurricular participation from high school to college. Am. J. Educ. 95(3): 468-485.

Crawford, D. W., and Huston, T. L. (1993). The impact of the transition to parenthood on marital leisure. Person. Soc. Psychol. Bull. 19(1): 39-46.

Crowley, J. E. (1991). Educational status and drinking patterns: How representative are college students? J. Stud. Alcohol 52(1): 10-16.

Eccles, J. S., and Barber, B. L. (1999). Student council, volunteering, basketball, or marching band: What kind of extracurricular involvement matters? J. Adolesc. Res. 14(1): 10-43.

Entwisle, D. R., and Astone, N. M. (1994). Some practical guidelines for measuring youth's race/ethnicity and socioeconomic status. Child Devel. 65: 1521-1540.

Erikson, E. H. (1963). Childhood and Society (2nd edn.). Norton, New York.

Fasick, F. A. (1988). Patterns of formal education in high school as rites de passage. Adolescence 23(90): 457-468.

Fine, G. A., Mortimer, J. T., and Roberts, D. F. (1990). Leisure, work, and the mass media. In Feldman, S. S., and Elliot, G. R. (eds.), At the Threshold: The Developing Adolescent. Harvard University Press, Cambridge.

Flanagan, C., Schulenberg, J., and Fuligni, A. (1993). Residential setting and parent-adolescent relationships during the college years. J. Youth Adolesc. 22(2): 171-189.

Freysinger, V. J., and Ray, R. O. (1994). The activity involvement of women and men in young and middle adulthood: A panel study. Leis. Sci. 16(2): 193-217.

Furlong, A., Campbell, R., and Roberts, K. (1990). The effects of post-16 experiences and social class on the leisure patterns of young adults. Leis. Stud. 9(3): 213-224.

Gilligan, C. (1982). In a Different Voice. Harvard University Press, Cambridge.

Goldscheider, F. K., and Davanzo, D. (1986). Semiautonomy and leaving home in early adulthood. Soc. Forces 65(1): 187-201.

Greene, A. L., Wheatley, S. M., and Aldava, J. F. (1992). Stages on life's way: Adolescents' implicit theories of the life course. J. Adolesc. Res. 7(3): 364-381.

Henderson, K. A. (1990). The meaning of leisure for women: An integrative review of the research. J. Leis. Res. 22(3): 228-243.

Hendry, L. B. (1989). The influence of adults and peers on adolescents' lifestyles and leisure styles. In K. Hurrelman and U. Engel (eds.), The Social World of Adolescents: International Perspectives. Walter de Gryter, Berlin, pp. 245-263.

Hoff, A. E., and Ellis, G. D. (1992). Influence of agents of leisure socialization on leisure self-efficacy of university students. J. Leis. Res. 24(2): 114-126.

Holman, T. B., and Epperson, A. (1984). Family and leisure: A review of the literature with research recommendations. J. Leis. Res. 16(4): 277-294. 
Horna, J. (1989). The leisure component of the parental role. J. Leis. Res. 21(3): 228-241.

Huston, T. L., and Ashmore, R. D. (1985). Women and men in personal relationships. In Ashmore, R. D., and Del Boca, F. K. (eds.), The Social Psychology of Female-Male Relations: A Critical Analysis of Central Concepts Academic Press, Orlando, pp.167-210.

Iso-Ahola, S. E. (1980). The Social Psychology of Leisure and Recreation. Wm. C. Brown, Dubuque.

Iso-Ahola, S. E., and Buttimer, K. (1981). The emergence of work and leisure ethics from early adolescence to early adulthood. J. Leis. Res. 13: 282-288.

Kandel, D. B., and Raveis, V. H. (1989). Cessation of illicit drug use during young adulthood. Arch. Gen. Psychiat. 46: 109-116.

Kelly, J. R., and Godbey, G. (1992). The Sociology of Leisure. Venture, State College, PA.

Kleiber, D. A., and Rickards, W. H. (1985). Leisure and recreation in adolescence: Limitation and potential. In Wade, M. G. (ed.), Constraints on Leisure. Charles C. Thomas, Springfield, Illinois, pp. 289-318.

Lindsay, P. (1984). High school size, participation in activities, and young adult participation: Some enduring effects of schooling. Educ. Eval. and Pol. Analys. 6(1): 73-83.

Marcia, J. E. (1966). Development and validation of ego identity status. J. Person. Soc. Psychol. 3(5): $551-558$.

Otto, L. B., and Alwin, D. F. (1977). Athletics, aspirations, and attainments. Sociol. Educ. 50: 102-113.

Otto, L. B., and Featherman, D. L. (1975). Social structural and psychological antecedents of selfestrangement and powerlessness. Am. Sociol. Rev. 40: 701-719.

Raymore, L. A. (1995). Leisure behavior and the transition from adolescence to young adulthood. Leis. Stud. 14: 202-216.

Raymore, L. A., Barber, B., Eccles, J., and Godbey, G. (1999). Leisure behavior pattern stability across the transition from adolescence to young adulthood. J. Youth Adolesc. 28(1): 79-103.

Rapoport, R., and Rapoport, R. N. (1975). Leisure and the Family Life Cycle. Routledge and Kegan Paul, Boston.

Schulenberg, J., Bachman, J. G., O’Malley, P. M., and Johnston, L. D. (1994). High school educational success and subsequent substance use: A panel analysis following adolescents into young adulthood. J. Health Soc. Behav. 35: 45-62.

Sherrod, L. R., Haggerty, R. J., and Featherman, D. L. (1993). Introduction: Late adolescence and the transition to adulthood. J. Res. Adolesc. 3(3): 217-226.

Surra, C. A. (1985). Courtship types: Variation in interdependence between partners and social networks. J. Person. Soc. Psychol. 49(2): 357-375.

Witt, P. A., and Goodale, T. L. (1981). The relationship between barriers to leisure enjoyment and family stages. Leis. Sci. 4(1): 29-49.

Zirkel, S., and Cantor, N. (1990). Personal construal of life tasks: Those who struggle for independence. J. Person. Soc. Psychol. 58: 172-185. 